\title{
Superior renoprotective effects of combination therapy with ACE and AGE inhibition in the diabetic spontaneously hypertensive rat
}

\author{
B. J. Davis ${ }^{1}$, J. M. Forbes ${ }^{1}$, M. C. Thomas ${ }^{1}$, G. Jerums ${ }^{2}$, W. C. Burns ${ }^{1}$, H. Kawachi ${ }^{3}$, T. J. Allen ${ }^{1}$, M. E. Cooper ${ }^{1}$ \\ ${ }^{1}$ Diabetic Complications Group, Baker Heart Research Institute, Prahran, Melbourne, Victoria, Australia \\ ${ }^{2}$ Department of Medicine, University of Melbourne, Austin \& Repatriation Medical Centre, Heidelberg, Victoria, Australia \\ ${ }^{3}$ Department of Cell Biology, Institute of Nephrology, Niigata University School of Medicine, Niigata, Japan
}

\begin{abstract}
Aims/hypothesis. Diabetic renal disease has been postulated to progress as a result of an interaction between metabolic and haemodynamic pathways. Our aim was to assess the functional, structural, molecular and cellular aspects of renal disease in an experimental model of diabetes with associated hypertension.

Method. Streptozotocin-induced diabetic spontaneously hypertensive rats were randomised to no treatment, the ACE inhibitor, perindopril $(2 \mathrm{mg} / \mathrm{l})$, the AGE formation inhibitor, aminoguanidine $(1 \mathrm{~g} / \mathrm{l})$ and a combination of both agents and were followed for 32 weeks. Results. Diabetes was associated with a considerable increase in albumin excretion rate. Both aminoguanidine and perindopril retarded the increase in albuminuria, which was completely abrogated by combination therapy. Glomerulosclerosis and tubulointerstitial damage was reduced by both monotherapies with further renoprotection afforded by combination therapy in
\end{abstract}

both cases. Combination therapy was also associated with a superior restoration in diabetes-induced nephrin protein depletion compared to either monotherapy. $T G F \beta 1$ expression as assessed by in situ hybridisation was increased in the diabetic rats and reduced by perindopril and aminoguanidine.

Conclusion/interpretation. These findings indicate that in the context of diabetes-related renal injury, blocking both the renin-angiotensin and advanced glycation pathways offers superior renoprotection and could be considered as a therapeutic strategy in the prevention and retardation of progressive-diabetic renal injury. [Diabetologia (2004) 47:89-97]

Keywords Diabetic nephropathy · albuminuria $\cdot$ glomerulosclerosis · tubulointerstitial injury · combination therapy · AGE formation · renin-angiotensin system · aminoguanidine . spontaneously hypertensive rat . transforming growth factor beta-1
Received: 13 June 2003 / Revised: 2 September 2003

Published online: 29 November 2003

(C) Springer-Verlag 2003

Dr. B. J. Davis $(\bowtie)$, Diabetic Complications Group, Baker Heart Research Institute, P.O. Box 6492, Prahran, Melbourne, Victoria, 8008 Australia

E-mail: belinda.davis@baker.edu.au

Abbreviations: AG, Aminoguanidine; AG/PER, aminoguanidine/perindopril; GS, glomerulosclerosis; PER, perindopril; RAS, renin-angiotensin system; SBP, systolic blood pressure; SHR, spontaneously hypertensive rat; STZ, streptozotocin; TGF $\beta 1$, transforming growth factor beta-1; TIA, tubulointerstitial area.
Based on clinical and experimental studies, the two main risk factors linked to the pathogenesis of diabetic vascular complications are hyperglycaemia and systemic hypertension [1, 2, 3, 4]. However, the interaction between these two pathways and their involvement in the pathogenesis of diabetic renal microvascular complications is not clear. Studies by our own group and others, in both the experimental and clinical setting have shown the renoprotective effects of antihypertensive agents that block the renin-angiotensin system (RAS) [1, 5, 6, 7]. The renal effects of these agents include reduced development of albuminuria and less glomerular and tubulointerstitial injury [8]. The effects of ACE inhibitors on renal structural injury have been mediated via the prosclerotic cytokine, 
TGF $\beta 1$ [9]. The antialbuminuric effects of agents which interrupt the RAS could partly be mediated by actions on expression of the slit pore protein, nephrin [10]. This protein, which is expressed exclusively by glomerular epithelial cells, has been implicated in the permeability of albumin across the glomerular barrier [11].

The view that hyperglycaemia has a role in the development of diabetic nephropathy arises not only from a large body of clinical and experimental evidence highlighting the beneficial effects of intensified glycaemic control [4, 12], but also from studies exploring the glucose-dependent pathway of advanced glycation. In this biochemical process, AGEs accumulate as a result of prolonged exposure of proteins to glucose. This AGE formation involves the non-enzymatic and irreversible glycation of long-lived tissue proteins and subsequent alteration of their conformation and physiological functions [13]. We have previously reported increased concentrations of AGEs in the rat kidney after 32 weeks of streptozotocininduced diabetes. Furthermore, a range of functional and structural parameters associated with diabetic nephropathy were ameliorated by aminoguanidine, a hydrazine-like compound that inhibits AGE formation [14]. Other studies have reported similar renoprotection with other inhibitors of AGE formation [15, 16, 17].

We investigated the potential synergistic effects of combining an agent that blocks the RAS with one that prevents the formation of AGEs. Specifically, we assessed if superior renoprotection is conferred with a combination of both agents when compared with either agent alone in the context of experimental diabetes. Following recent studies both in vitro [18] and in vivo [19] showing that ACE inhibitors can also inhibit AGE formation, we also assessed plasma and renal AGE concentrations with the various treatments. In addition, we explored the potential molecular mediators of renal functional and structural injury in diabetes by evaluating expression of the prosclerotic cytokine TGF $\beta 1$, and the slit-pore protein, nephrin.

\section{Subjects and methods}

Animal model. We used 8-week-old male spontaneously hypertensive rats (SHR), weighing 200 to $250 \mathrm{~g}$ housed in the Biological Research Laboratory at the Austin and Repatriation Medical Centre. The research project was approved by the Animal Welfare Committee of the Austin and Repatriation Medical Centre. Diabetes was induced by a single tail vein injection of streptozotocin (STZ) (Boehringer-Mannheim, Mannhein, Germany) at a dose of $45 \mathrm{mg} / \mathrm{kg}$ in citrate buffer after a 16-h fast [20]. Long-acting insulin (Protophane, Novo Nordisk Pharmaceuticals, Bagsvaerd, Denmark), at a dose of 4 U/day, was given to all diabetic rats by subcutaneous injection to avoid ketonuria and to promote weight gain. The rats had access to water and standard rat chow ad libitum.
Study groups. After inducing diabetes, the rats were randomly allocated into five groups and treated for 32 weeks as follows: diabetic SHR with no treatment (SHR-STZ), diabetic SHR treated with the AGE formation inhibitor, aminoguanidine (AG) (Fluka Chemicals, Stienheim, Switzerland) at a dose of $1 \mathrm{~g} / \mathrm{l}$ in the drinking water, diabetic SHR treated with the ACE inhibitor, perindopril (PER) (Servier, Neuilly, France) at a dose of $1.25 \mathrm{mg} \cdot \mathrm{kg}^{-1} \cdot \mathrm{day}^{-1}$ in drinking water, and diabetic SHR treated with the combination of perindopril and aminoguanidine (AG/PER) at the same doses as used in monotherapy, both agents administered in the drinking water. The dose of ACE inhibition was chosen to be antihypertensive, but was not administered at the maximum dose so that potential synergistic or additive effects of AG could be determined. In addition, nondiabetic SHRs, sham injected with citrate buffer served as the control rats and were studied concurrently.

Physiological and metabolic parameters. The rats were placed in metabolic cages every 4 weeks (Iffa Credo, L'Arbesele, France) for collection of urine over $24 \mathrm{~h}$ to measure the albumin concentration by radioimmunoassay as described previously [14]. Systolic blood pressure (SBP) was assessed by tail cuff plethsymography in conscious, preheated rats [21] every 4 weeks. $\mathrm{HbA}_{1 \mathrm{c}}$ was measured by a high performance liquid chromatography method (Bio-Rad, Richmond Laboratories, Richmond, Va., USA) [22]. At week 32 the rats were killed by decapitation and their organs were harvested. The left kidney was fixed in either $4 \%$ paraformaldehyde or neutral buffered formalin for subsequent histological studies.

Glomerulosclerosis. The degree of glomerulosclerosis (GS) was evaluated by a semi-quantitative method as described previously [23]. Kidney sections were stained with haematoxylin and eosin and observed under a light microscope in a blinded fashion at a magnification of $\times 400$ using the Imaging Analysis System (AIS, Imaging Research, St. Catherines, Ontario, Canada). Forty glomeruli from each kidney were graded according to the severity of the glomerular damage: 0 , normal; 1 , slight glomerular damage, the mesangial matrix and/or hyalinosis with focal adhesion, involving less than $25 \%$ of the glomerulus; 2, sclerosis of 25 to $50 \%$; 3 , sclerosis of 50 to $75 \% ; 4$, sclerosis of more than $75 \%$ of the glomerulus. The indices for glomerulosclerosis was calculated by using the following formula:

$$
\begin{aligned}
G S= & \left(1 \times n_{1}\right)+\left(2 \times n_{2}\right)+\left(3 \times n_{3}\right) \\
& +\left(4 \times n_{4}\right) / n_{0}+n_{1}+n_{2}+n_{3}+n_{4}
\end{aligned}
$$

Where $\mathrm{n}_{\mathrm{x}}=$ number of glomeruli in each grade of glomerulosclerosis.

Tubulointerstitial area. Point counting was done in the renal cortex and in the corticomedullary junction for each rat following routinely established methods [24]. In each field, 100 points were counted on a $1 \mathrm{~cm}^{2}$ eyepiece graticule with 10 equidistant grid lines. A total of 12 high power fields $(\times 400)$ per section were counted for each rat in all groups in the corticomedullary field. Each high power field was $0.076 \mathrm{~mm}^{2}$ with $0.91 \mathrm{~mm}^{2}$ being the total area counted per slide. [24]:

The percent fractional area (FA) was calculated as follows

$\% F A=$

number of tubulointerstitial grid intersections $\times 100$ total number of grid intersections

This corresponds to the percentage of the tubulointerstitial area (TIA) in the total area counted of the section. 
In situ hybridisation. The site-specific expression of TGF $\beta 1$ mRNA was determined by in situ hybridisation, and carried out as reported $[25,26]$. Briefly, four micron kidney sections were hybridised after digestion with PronaseE at $37^{\circ} \mathrm{C}$. The hybridization buffer containing $2 \times 10^{4} \mathrm{cpm} / \mu \mathrm{l}{ }^{35} \mathrm{~S}$ labelled riboprobe, $0.72 \mathrm{mg} / \mathrm{ml}$ yeast RNA, $50 \%$ deionized formamide, $100 \mathrm{mmol} / \mathrm{l}$ DTT, $10 \%$ dextran sulfate, $0.3 \mathrm{~mol} / \mathrm{l} \mathrm{NaCl}$, $10 \mathrm{mmol} / 1 \mathrm{Na}_{2} \mathrm{HPO}_{4}, 10 \mathrm{mmol} / \mathrm{l} \mathrm{pH} 7.5$ and $5 \mathrm{mmol} / \mathrm{l}$ EDTA $\mathrm{pH} 8.0,0.02 \%$ BSA, $0.02 \%$ Ficoll 400 , and $0.02 \%$ PVP was added to each section and incubated at $60^{\circ} \mathrm{C}$ overnight. Following stringent washing with $50 \%$ formamide, $2 \times \mathrm{SSC}$ at $55^{\circ} \mathrm{C}$ the slides were air-dried and exposed to BioMax MR film (Kodak Company, Rochester, N.Y., USA) for 3 to 5 days. Slides were coated with desiccant for a period of 2 to 4 weeks according to the autoradiography results. The slides were developed using Kodak D19 developer for $4 \mathrm{~min}, 1 \%$ acetic acid for 1 min and Ilford Hypan fixative for 4 min followed by rinsing in distilled water for at least $15 \mathrm{~min}$. The sections were then fixed in $4 \%$ paraformaldehyde and treated with a progressive haematoxylin/eosin stain. Quantitation of the data was done on the renal cortex and on the corticomedullary junction from the autoradiography film. The probe binding density was determined by computerised densitometry. Before each analysis session the analysis software was densitometrically calibrated to the Linotype-Hell scanner using an AGFA transmissive greyscale step wedge. The densitometric values for the AGFA step wedge were acquired using an optically calibrated densitometer. Using a densitometrically calibrated look-up table, greyscale values were converted to optical density values.

Nephrin immunostaining. Immunohistochemistry was done according to a modified method using a specific antibody to mAb 5-1-6 antigen which is identical to rat nephrin [10, 27]. This antibody was raised in the rabbit against a synthetic peptide sequence derived from the cytoplasmic region of the nephrin protein $[10,27]$. In brief, $4 \mu \mathrm{m}$ frozen kidney sections were cut on a cryostat at $-20^{\circ} \mathrm{C}$. Frozen sections were fixed with cold acetone for $10 \mathrm{~min}$. Endogenous peroxidase was inactivated using $0.1 \%$ hydrogen peroxide in phosphate-buffered saline for $10 \mathrm{~min}$, then sections were incubated with protein blocking agent for $20 \mathrm{~min}$. Endogenous non-specific binding for biotin and avidin was blocked using a Biotin/Avidin blocking Kit (Vector Laboratories, Burlingame, Calif., USA). The kidney sections were incubated for $1 \mathrm{~h}$ at room temperature with mAb 5-1-6 antibody. Biotinylated goat anti-mouse immunoglobulin (Victor Laboratories, Burlingame, Calif., USA) was used as a second antibody, followed by horseradish peroxidase-conjugated streptavidin. Peroxidase activity was identified by reaction with 3,3'-diaminobenzidine tetrahydrochloride (DAB, Sigma Chemical, St Louis, Mo., USA) substrate. Quantification of nephrin immunostaining was done by calculating the proportion of area occupied by the brown staining within each glomerulus [28]. An observer who was masked to the study group of origin assessed twenty glomeruli per slide and eight slides per rat.

\section{Measurement of AGEs}

Serum levels. AGE-peptides were quantified using the flowinjection method as reported previously [19, 29]. Briefly, $20 \mu \mathrm{l}$ of serum was added to $480 \mu \mathrm{l}$ of $0.15 \mathrm{~mol} / \mathrm{l}$ trichloroacetic acid (to remove protein) and $100 \mu \mathrm{l}$ of chloroform (to remove lipid). Twenty microlitres of the aqueous phase was then injected into the flux phase of a flow injector system and monitored in series detectors monitoring AGE-fluorescence at $440 \mathrm{~nm}$ (emission) and $247 \mathrm{~nm}$ (excitation) and measuring absorbance at $280 \mathrm{~nm}$ (peptide content). The results are expressed as a percent defined by a ratio of the area under the fluorescence curve divided by the area under the curve (i.e. fluorescence per peptide content) compared to that of standard AGE-peptides obtained from enzymatic hydrolysis of $10 \mathrm{mg} / \mathrm{ml}$ AGE-BSA.

Tissue levels. The concentration of total protein determined using a BCA protein assay kit (Pierce, Rockford, Ill., USA) was measured in homogenised whole kidney, previously stored at $-80^{\circ} \mathrm{C}$. Renal AGE peptide fluorescence was measured in 24-h acid-hydrolysed protein preparations by a flow injection system [29] with a Waters 470 spectrophotometer (370/ $440 \mathrm{~nm}$, Waters, Milford, Mass., USA). To correct for differences in sample protein content, fluorescence intensity was expressed as arbitrary units of fluorescence per $\mathrm{mg} /$ collagen.

Statistics. All data are shown as means \pm SEM unless otherwise specified. Since the data for albuminuria are not normally distributed, logarithmic transformation was done prior to analysis and data are shown as geometric mean $\times / \div$ tolerance factor (Geometric SEM). Data were initially analysed by ANOVA with post hoc comparisons between group means carried out by Fisher's least significant difference method [30] using Statview version 5.0. A $p$ value of less than 0.05 was viewed as statistically significant.

\section{Results}

Metabolic parameters, blood pressure and kidney weight. Diabetes was associated with reduced bodyweight gain. No effect on body weight was observed with monotherapy treatments, although the aminoguanidine and perindopril combination was associated with less body-weight gain (Table 1 ). $\mathrm{HbA}_{1 \mathrm{c}}$ was increased in all diabetic groups. Combination AG/PER

Table 1. Body weight, glycated haemoglobin and kidney weight-to-body weight ratio (KW/BW) at week 32 of the study period

\begin{tabular}{lllll}
\hline Treatment & $n$ & Body weight $(\mathrm{g})$ & $\mathrm{HbA}_{1 \mathrm{c}}(\%)$ & $\mathrm{KW} / \mathrm{BW}(\mathrm{g} / \mathrm{kg})$ \\
\hline Control & 15 & $458 \pm 9$ & $4.7 \pm 0.4$ & $3.3 \pm 0.1$ \\
Diabetic & 16 & $359 \pm 9^{\mathrm{a}}$ & $12.3 \pm 0.3^{\mathrm{a}}$ & $4.5 \pm 0.1^{\mathrm{a}}$ \\
Perindopril & 17 & $357 \pm 5^{\mathrm{a}}$ & $11.9 \pm 0.2^{\mathrm{a}}$ & $4.4 \pm 0.2^{\mathrm{a}}$ \\
Aminoguanidine & 18 & $352 \pm 9^{\mathrm{a}}$ & $10.4 \pm 0.4^{\mathrm{a}, \mathrm{c}}$ & $4.5 \pm 0.1^{\mathrm{a}}$ \\
Aminoguanidine +Perindopril & 16 & $337 \pm 6^{\mathrm{a}, \mathrm{b}}$ & $10.3 \pm 0.4^{\mathrm{a}, \mathrm{c}}$ & $4.7 \pm 0.1^{\mathrm{a}}$ \\
\hline
\end{tabular}

Data are shown as means \pm SEM.

${ }^{\mathrm{a}} p<0.01$ vs control rats; ${ }^{\mathrm{b}} p<0.05,{ }^{\mathrm{c}} p<0.01$ vs untreated diabetic rats 
therapy and AG as monotherapy had a modest effect on glycated haemoglobin. Kidney enlargement was observed in the diabetic untreated rats, which was not reduced by any of the treatment groups.

\section{Functional changes}

Systolic blood pressure. Diabetes was associated with reduced SBP when compared to the control rats over the 32-week study period (ANOVA; $\mathrm{F}=74.4, p<0.001$; average week 8-32 control rats $210 \pm 2$ vs untreated diabetic group, $185 \pm 2 \mathrm{mmHg}, p<0.001$; Fig. 1). Perindopril reduced SBP by approximately $30 \mathrm{mmHg}$ when compared to untreated diabetic rats (ANOVA; $\mathrm{F}=$ $117, p<0.001$; average week 8-32 PER 153 $2 \mathrm{mmHg} p<0.001$ vs diabetic) as did the AG/PER group, (ANOVA; $\mathrm{F}=120, p<0.001$; average week 8-32 AG/PER $156 \pm 2 \mathrm{mmHg}, p<0.001$ vs diabetic, NS vs diabetic + PER). There was no statistically significant difference in blood pressure between the PER and AG/PER treated groups. Aminoguanidine alone did not reduce SBP to any significant extent (average week 8-32, AG alone $180 \pm 4 \mathrm{mmHg}$ ).

Albuminuria. Four weekly serial measurements of AER for week 16 to week 32 of the study period are shown in Fig. 2. Diabetes was associated with a progressive rise in albuminuria compared with non-diabetic SHR during the study period (ANOVA; $\mathrm{F}=69.9$, $p<0.001$; week 32 diabetes $145.9 \times / \div 1.1 \mathrm{mg} / 24 \mathrm{~h}$ vs control rats $48.9 \times / \div 1.2 \mathrm{mg} / 24 \mathrm{~h}, p<0.001)$. Perindopril retarded the increase in albuminuria compared to the untreated diabetic group over the treatment period (ANOVA; $\mathrm{F}=19.0, \quad p<0.001$; week 32 PER $97.1 \times / \div 1.1 \mathrm{mg} / 24 \mathrm{~h}$, vs diabetic untreated, $p<0.001$ ),

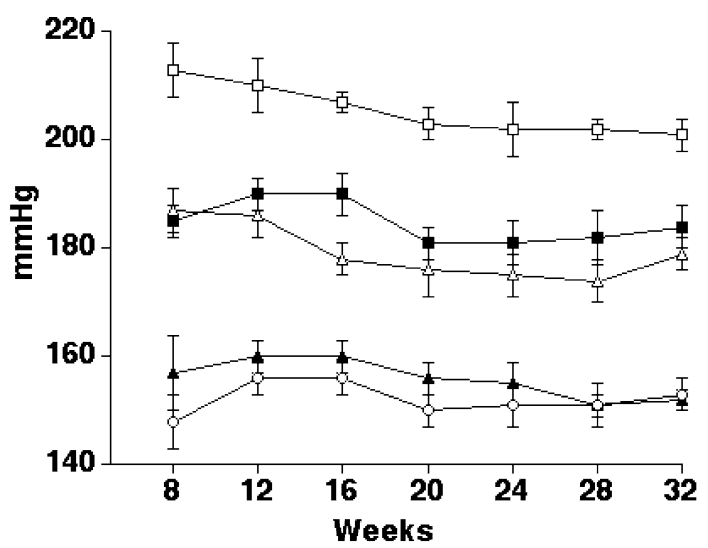

Fig. 1. Serial measurements every 4 weeks of systolic blood pressure are shown for weeks 8 to 32 of the study period for the control rats (white squares), untreated diabetic (black squares), diabetic + PER (white circles), diabetic + AG (white triangles) and diabetic $+\mathrm{AG} / \mathrm{PER}$ (black triangles). Control vs diabetic rats $\mathrm{F}=74, p<0.001$; diabetic + PER $\mathrm{F}=117, p<0.001$; diabetic vs AG $\mathrm{F}=2, p<0.1$; diabetic vs AG/PER $\mathrm{F}=120$, $p<0.001$ ANOVA with repeated measures)

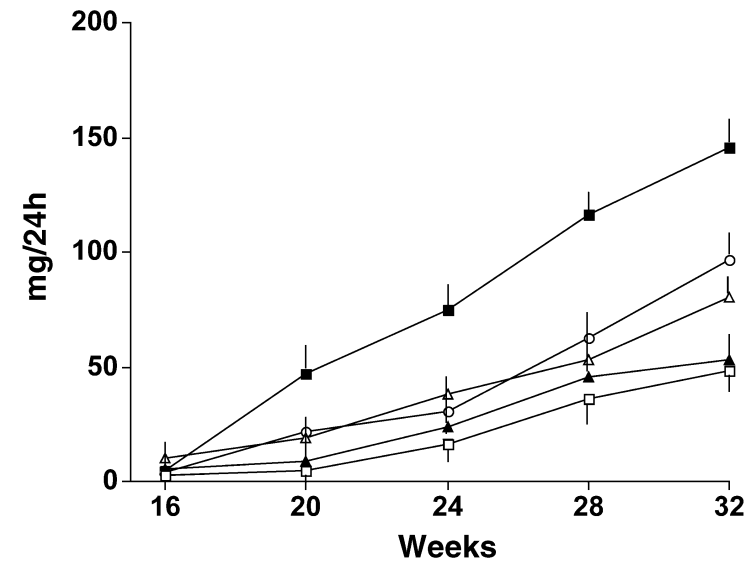

Fig. 2. Serial monthly measurements of albumin excretion rate every 4 weeks are shown for weeks 16 to 32 of the study period for the control rats (white squares), untreated diabetic rats (black squares), diabetic + PER (white circles), diabetic + AG (white triangles) and diabetic + AG/PER (black triangles). Geometric means and tolerance factors are shown. Control vs diabetic rats $\mathrm{F}=69.9, p<0.001$; diabetic vs $\mathrm{PER} \mathrm{F}=19.0$, $p<0.001$; diabetic vs AG $\mathrm{F}=8.6, p<0.01$; diabetic vs AG/PER $\mathrm{F}=40.1, p<0.001$ ANOVA with repeated measures)

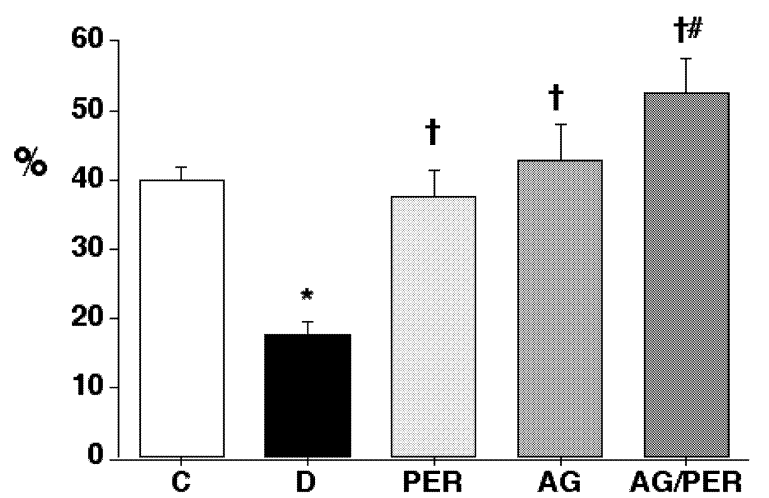

Fig. 3. Quantitation for the immunohistochemical staining for nephrin protein expression. Data are shown as means \pm SEM. $\mathrm{C}$, control rats; $\mathrm{D}$, diabetic untreated rats; PER, diabetic + perindopril; AG, diabetic + aminoguanidine; AG/PER, diabetic + aminoguanidine + perindopril. $* p<0.001$ vs control rats, $\dagger p<0.001$ vs untreated diabetic rats, $\# p<0.05$ vs PER

as did the aminoguanidine group (ANOVA; $\mathrm{F}=8.6$, $p<0.01$; week $32 \mathrm{AG}, 80.4 \times / \div 1.3 \mathrm{mg} / 24 \mathrm{~h}$, vs diabetic untreated, $p<0.01)$. The combination of perindopril and aminoguanidine attenuated the development of albuminuria in the diabetic rats (ANOVA; $\mathrm{F}=40.1$, $p<0.001$; week 32 AG/PER $59.5 \div 1.1 \mathrm{mg} / 24 \mathrm{~h}$, vs diabetic untreated $p<0.001)$. This attenuation in the combination group was greater than that observed with either monotherapy treatment (AG/PER vs PER, $\mathrm{F}=7.7, p<0.01 ; \mathrm{AG} / \mathrm{PER}$ vs $\mathrm{AG}, \mathrm{F}=4.5, p<0.02)$.

Nephrin protein expression. Diabetes was associated with a decrease in nephrin protein expression compared to the control SHR group (control, $40.0 \pm 1.9$ vs untreated diabetic rats, $18.6 \pm 1.9 \%$; $p<0.001$ ) (Fig. 3). 

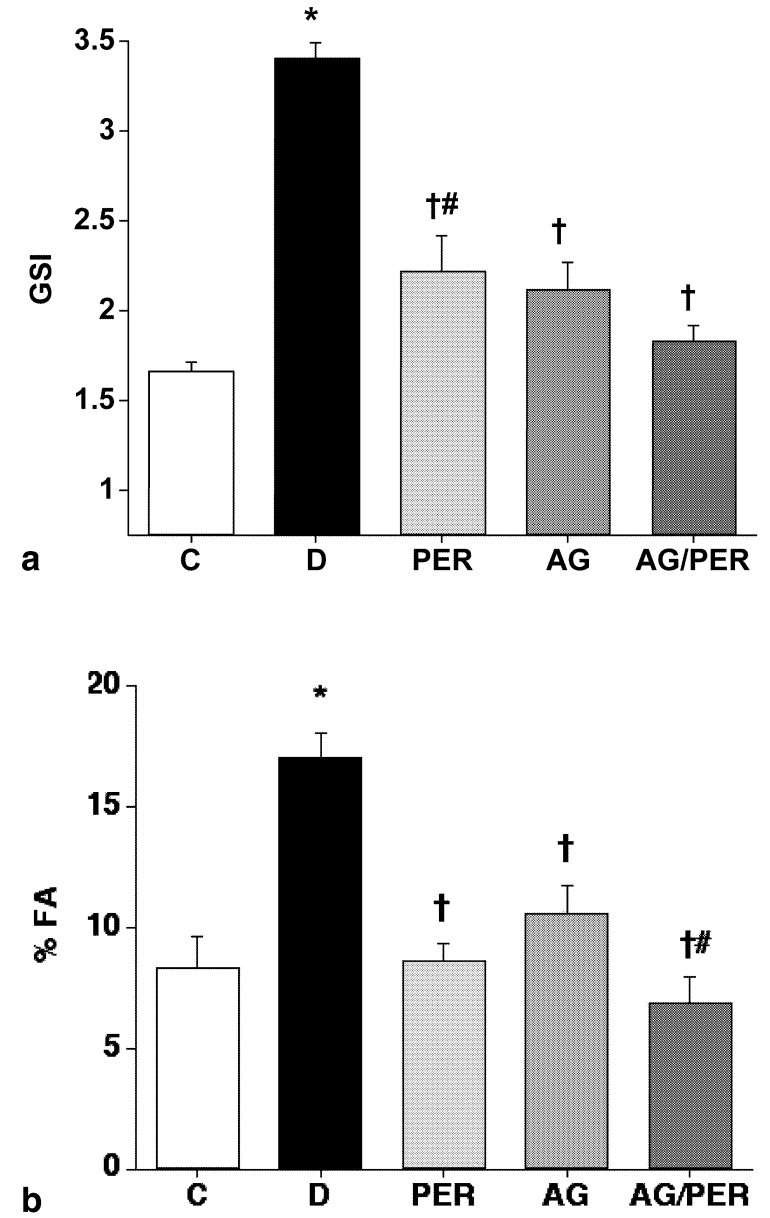

Fig. 4a, b. Glomerulosclerosis index (a) and tubulointerstitial area (b) are shown as mean \pm SEM. C-control rats; D-diabetic untreated rats; PER-diabetic + perindopril; AG-diabetic + aminoguanidine; AG/PER - diabetic + aminoguanidine + perindopril. ${ }^{*} p<0.001$ vs control rats, $\dagger p<0.01$ vs untreated diabetic rats, $\# p<0.01$ vs AG/PER

Both PER and AG treatment groups prevented this decrease in glomerular nephrin expression (PER, $37.6 \pm 3.9 \%$; AG, 42.7 $\pm 5.3 \% ; p<0.001$ vs untreated diabetic) with an additional effect observed with the combination group (AG/PER 52.6 $\pm 2.5 \%, p<0.001$ vs untreated diabetic; $p<0.05$ vs PER alone).

Glomerulosclerotic index (GSI). The GSI was higher in the diabetic SHR group compared to the control group (Table 1, Fig. 4a). Both AG and PER treatment groups reduced the GSI, with a further reduction in the AG/PER treated group when compared to the PER only group $(p<0.05)$.

Tubulointerstitial area (TIA). Tubulointerstitial injury was increased in the diabetic untreated group compared to the control SHR group (Table 1, Fig. 4b). There was a decrease in tubulointerstitial area in the AG and PER groups, which was further decreased by the AG/PER group compared to the AG treatment only group.
Cytokine gene expression: TGF $\beta 1$. Diabetes was associated with an increased expression of TGF $\beta 1 \mathrm{mRNA}$ (Fig. 5a, b), which was normalised by all treatments including PER, AG and the combination regimen (Fig. 5b).

Quantitation of AGE concentrations: Serum AGE concentrations. Diabetes was associated with a significant increase in serum AGE concentrations compared to the control SHR (Fig. 6A). Both aminoguanidine and perindopril significantly reduced the concentration of serum AGEs compared to the untreated diabetic group. The AG/PER combination reduced the concentration of serum AGEs below that of control values although this was not significantly lower than either monotherapy.

Tissue AGE concentrations. The diabetic untreated group had an increased concentration of tissue AGE fluorescence compared to the control group (control $8.1 \pm 1.4$ vs untreated diabetic $14.7 \pm 1.5$ arbitrary units/mg protein; $p<0.01$; Fig. $6 b$ ). This was reduced by both treatment groups as monotherapy. There was no additional reduction in AGE fluorescence afforded by the combination group treatment.

\section{Discussion}

Our study shows that the combination of an agent that interrupts the renin-angiotensin system with one that inhibits AGE formation provides superior renoprotection in a model of experimental diabetes, than either agent alone. This has been shown for a range of functional and structural parameters including albuminuria, glomerulosclerosis and tubulointerstitial injury. The results support the concept that the pathogenesis of diabetic nephropathy involves a deleterious interaction between haemodynamic and metabolic pathways [31]. These observations should be considered in the context of the beneficial effects of both ACE and AGE inhibitors on the progression of renal damage in the experimental context $[5,14,15,32]$.

It has been well established that blood pressure is a major determinant in the progression of diabetic complications, including nephropathy [3, 20]. Previous studies by many researchers including our own laboratory have shown the renoprotective effect of reducing blood pressure in retarding the progression of experimental diabetic nephropathy. As expected, treatment in this study with the ACE inhibitor, perindopril was associated with an antihypertensive and antialbuminuric effect, as has been shown with other agents that block the RAS [1, 5, 7]. It is likely that the renoprotective effect of blocking the RAS includes effects not only via specific reductions in pathways dependent on blood pressure, but also in attenuation of non-haemodynamic effects of angiotensin II. A study in this model of 

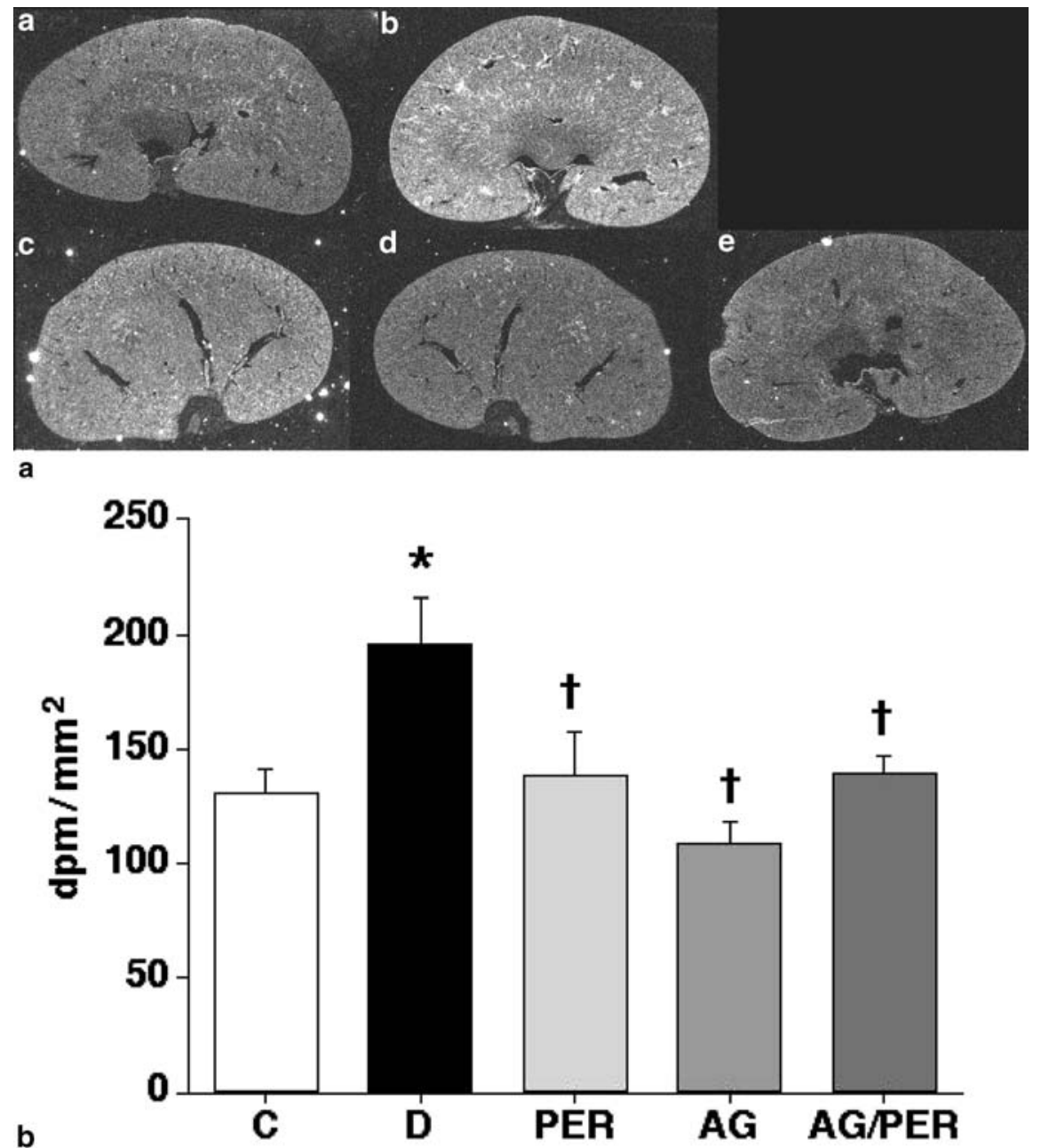

Fig. 5a,b. (a) X-ray autoradiograph film of $T G F \beta 1$ in situ hybridisation of kidney from the control rats (a), untreated diabetic rats (b), PER (c), AG (d) and AG/PER (e). Original magnification $\times 4$. (b) Quantitation of the in situ hybridisation for the gene expression of TGF $\beta 1$. Data are shown as means \pm SEM. C, control rats; D, diabetic untreated rats; PER, diabetic + perindopril; AG, diabetic + aminoguanidine; AG/PER, diabetic + aminoguanidine + perindopril. $* p<0.001$ vs control rats, $\uparrow p<0.01$ vs untreated diabetic rats

hypertension and diabetes has shown that, despite an equihypotensive effect of the angiotensin II receptor blocker, valsartan and the dihydropyridine calcium channel blocker, amlodipine, renoprotection as assessed by reductions in albuminuria and glomerulosclerosis was afforded by valsartan only [33]. As angiotensin II (AII), the effector peptide of the RAS, has been shown to have growth-like properties $[34,35]$ the beneficial effects observed with perindopril, and thus the progression of albuminuria in this model, may only partly be explained by effects on systemic blood pressure. Angiotensin II has been implicated in the stimulation of transforming growth factor $\beta 1$ (TGF $\beta 1$ ), a prosclerotic cytokine considered pivotal in the progression of diabetic renal complications $[8,36]$.
Aminoguanidine treatment was also associated with an attenuation of albuminuria, despite no antihypertensive effect. The ability of the inhibition of AGE, aminoguanidine to confer antialbuminuric effects has been shown by other studies in normotensive [37] and hypertensive transgenic Ren-2 rats [38] as well as in studies involving AGE infusion [39]. However, the exact mechanism through which aminoguanidine exerts an antialbuminuric effect is not clear. It has been postulated that the dysfunction of the extracellular matrix turnover in diabetes leads to an accumulation of AGEs, resulting in mesangial expansion and basement membrane thickening, both of which are hallmarks of diabetic nephropathy [40, 41]. The ability of aminoguanidine to reduce AGE accumulation in the kidney, thus partially preserving alterations in the glomerular filtration process could account for the positive effects on albuminuria in this study. Indeed, aminoguanidine treatment was associated with a reduction in diabetes-related increases in renal AGEfluorescence. A reduction in AGE-fluorescence was also observed in the perindopril-treated group. Previous studies by our group and others have documented the anti-AGE effect of RAS blockade both in vivo [19] and in vitro [18]. Whether this reflects the ability of AII to influence AGE production, improve renal 


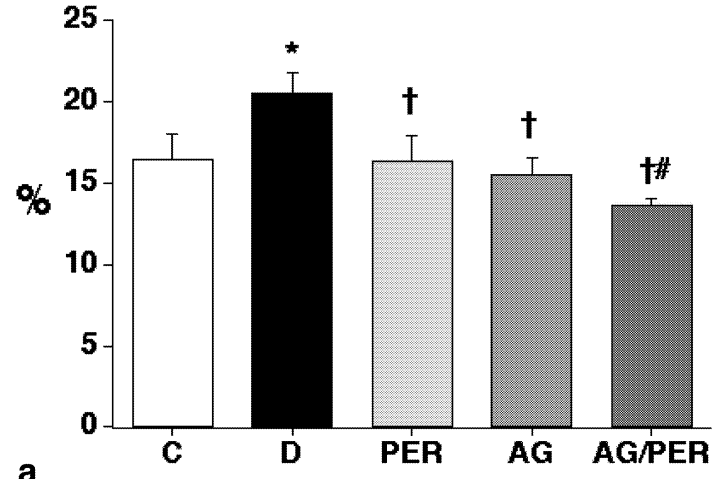

a

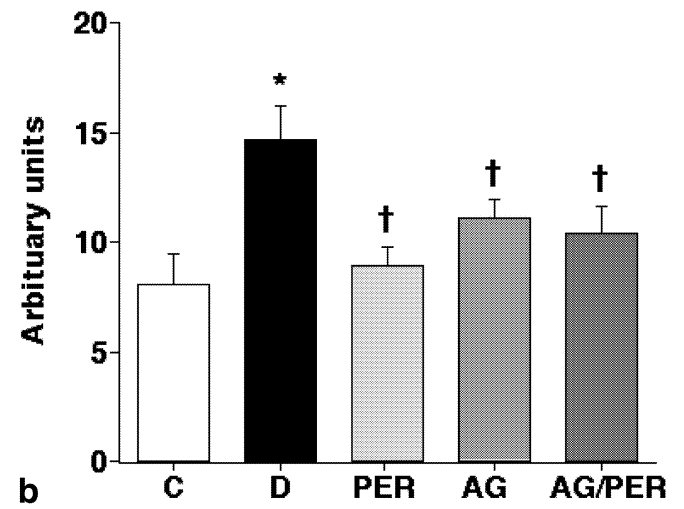

Fig. 6a, b. Quantitation of serum (a) and tissue (b) concentrations of AGEs. Data are shown as means \pm SEM. C, control rats; D, diabetic untreated rats; PER, diabetic + perindopril; AG, diabetic + aminoguanidine; AG/PER, diabetic + aminoguanidine + perindopril. $* p<0.001$ vs control rats, $\uparrow p<0.01$, $\# p<0.001$ vs untreated diabetic rats

clearance of AGEs or reduce tissue injury related to oxidative stress $[19,42]$ has not yet been determined. Increases in serum AGEs, as observed in the diabetic rats in this and other studies [15, 37, 39] have been associated with impairment of renal function [43]. However, impairment of renal function is not a prominent feature of this model [20].

It is unlikely that the renoprotective effects of $A G$ are related to its ability to inhibit the inducible form of nitric oxide synthase. One study showed no significant changes in the progressive rise in albuminuria between AG and ALT-946, a potent inhibitor of AGEderived protein modification that has a minimal effect on NOS inhibition [15]. In addition, other agents which inhibit AGE formation such as OPB-9195 [16] and pyridoxamine [17] retard the development of albuminuria, yet have no effect on nitric oxide synthesis. This is further suggested by our previous research showing that inhibition of NOS with L-NAME and methylguanidine failed to provide similar renoprotection to that seen with aminoguanidine [44].

In this study we observed a superior effect of combination therapy in attenuating the progression of albuminuria when compared to either agent as mono- therapy. This was also in association with preservation of the diabetes-related depletion in nephrin, a slit-pore protein established to play a role in the glomerular filtration process $[11,45]$. Our group and others have documented the prevention of nephrin depletion in both normotensive [46] and hypertensive [10, 33] models of diabetic renal injury with RAS blockade. These effects occurred in association with a concomitant reduction in the rise of albumin excretion rate. In this study we show a prevention of nephrin depletion, as assessed by immunohistochemistry, in association with both perindopril and aminoguanidine as monotherapies. There was a further increase in nephrin expression observed with the combination therapy in association with a superior effect on urinary albumin excretion. Since combination therapy was associated with the highest level of glomerular nephrin expression, and both aminoguanidine and perindopril as monotherapies preserve glomerular nephrin depletion in this model, it is likely that diabetes-associated nephrin depletion is mediated by both metabolic and haemodynamic pathways.

One potential explanation for the renoprotective effect of combination therapy could be that this treatment was associated with reduced food intake, thereby leading to reduced protein intake, a known determinant of progression of renal disease in experimental diabetes [47]. We did not use a maximal dose of ACE inhibition since higher doses of this agent, as previously reported [48], would have conferred superior renoprotection and therefore would not have allowed us to assess potential synergistic or additive effects of alternative treatments such as an inhibitor of advanced glycation.

The renal structural injury observed in the diabetic rats, as assessed in both the glomerulus and tubulointerstitium, was reduced by both treatments as monotherapy, with an additional effect observed with the combination when compared to either perindopril or aminoguanidine treatment alone. The reduction in glomerular and tubulointerstitial injury was observed in association with a reduction in the expression of the prosclerotic cytokine, TGF $\beta 1$ in all three treatment groups. Both ACE and AGE inhibition reduce the degree of glomerulosclerosis possibly via a reduction in the expression of prosclerotic cytokines such as TGF $\beta 1[8,49,50]$. Our results further support to the concept that both AII and AGE formation are implicated in the progression of glomerular structural injury via a common cytokine pathway such as TGF $\beta 1$. However, as combination therapy reduced the glomerular injury more than seen with either monotherapy alone, yet no additional reduction in TGF $\beta 1$ gene expression was observed. This would imply that other factors could also be involved including growth factors such as PDGF [49] or CTGF [51] which have been shown to be AGE-dependent.

Aminoguanidine and perindopril were not only associated with a decrease in glomerulosclerosis, but 
also had effects on reducing tubulointerstitial injury. The tubulointerstitium is now considered a major site of diabetes-related injury and is an important determinant of the rate of decline in renal function in diabetic nephropathy [9]. Combination therapy was associated with a further reduction in tubulointerstitial injury, and in particular was superior to aminoguanidine than to ACE inhibition. It is not clear if AII rather than AGEdependent pathways predominate in the tubulointerstitium in diabetes. Although it has been shown in vivo and in vitro that there are AGE-mediated pathways which seem to be important in the development of tubulointerstitial injury [52], the superior effect of ACE versus AGE formation inhibition on improvement of tubular injury was recently observed in a diabetic model of hypertension and severe structural injury $[38,53]$. However, in that study using the hypertensive Ren-2 model, there is local activation of the intrarenal renin-angiotensin system [53], a phenomenon not observed in the model used in our study, the SHR. Neither treatment influenced body weight, which is primarily related to tubular hypertrophy. Indeed, ACE inhibition has been reported not to affect tubular hypertrophy.

We found evidence supporting the concept that both metabolic and haemodynamic factors contribute to the development of diabetic nephropathy. It is evident that both pathways are mediating the progression of the disease and a potential common pathway could involve the prosclerotic cytokine, TGF $\beta 1$. The effect of the ACE inhibitor on TGF $\beta 1$ mRNA expression could be due to the reduction on AII mediated effects and also to the reduced mechanical forces as a result of reduced systemic blood pressure. However, the ability of an AGE inhibitor to reduce TGF $\beta 1$ expression without influencing systemic blood pressure, emphasises the role of non-haemodynamic effects of mediators such as AII and AGEs on TGF $\beta$ expression.

This study contributes to our understanding of the multifactorial nature of diabetic nephropathy and implies that therapeutic intervention for this condition may require an approach involving different agents to inhibit the various putative pathogenic pathways. Presumably such an approach could include both AGE and ACE inhibition.

Acknowledgements. This research was supported by funding from the Juvenile Diabetes Foundation International (JDRF) and the National Health and Medical Research Council of Australia. B.J. Davis and M.C. Thomas are recipients of NHMRC Dora Lush $\mathrm{PhD}$ scholarship. J.M. Forbes is a recipient of a JDRF Post Doctoral Fellowship. W.C. Burns is a recipient of an Australian Kidney Foundation Scholarship. The authors would like to thank Ms. K. Goldring, Mr. G. Langmaid and Ms. P. Aldersea, for animal care. The authors would also like to thank Ms. V. Thallas and Mrs. M. Arnstein for technical assistance.

\section{References}

1. Lewis EJ, Hunsicker LG, Bain RP, Rohde RD (1993) The effect of angiotensin converting enzyme on diabetic nephropathy. N Engl J Med 329:1456-1462

2. Cooper ME (1998) Pathogenesis, prevention, and treatment of diabetic nephropathy. Lancet 352:213-219

3. Adler AI, Stratton IM, Neil HAW et al. (2000) Association of systolic blood pressure with macrovascular and microvascular complications of type 2 diabetes (UKPDS 36): prospective observational study. BMJ 321:412-419

4. Stratton IM, Adler AI, Neil HAW et al. (2000) Association of glycaemia with macrovascular and microvascular complications of type 2 diabetes (UKPDS 35): prospective observational study. BMJ 321:405-412

5. Cooper ME, Allen TJ, Macmillan PA, Clarke BE, Jerums G, Doyle AE (1989) Enalapril retards glomerular basement membrane thickening and albuminuria in the diabetic rat. Diabetologia 32:326-328

6. Coats AJS (2001) Angiotensin receptor blockers-finally the evidence is coming in: IDNT and RENAAL. Int J Cardiol 79:99-102

7. Andersen S, Tarnow L, Rossing P, Hansen BV, Parving HH (2000) Renoprotective effects of angiotensin II receptor blockade in type 1 diabetic patients with diabetic nephropathy. Kidney Int 57:601-606

8. Gilbert RE, Cox A, Wu LL et al. (1998) Expression of transforming growth factor-betal and type IV collagen in the renal tubulointerstitium in experimental diabetes: effects of ACE inhibition. Diabetes 47:414-422

9. Gilbert RE, Cooper ME (1999) The tubulointerstitium in progressive diabetic kidney disease: more than an aftermath of glomerular injury? Kidney Int 56:16271637

10. Bonnet F, Cooper ME, Kawachi H, Allen TJ, Boner G, Cao Z (2001) Irbesartan normalises the deficiency in glomerular nephrin expression in a model of diabetes and hypertension. Diabetologia 44:874-877

11. Ruotsalainen V, Ljungberg P, Wartiovaara J et al. (1999) Nephrin is specifically located at the slit diaphragm of glomerular podocytes. Proc Natl Acad Sci USA 96:7962-7967

12. DCCT Research Group (1995) Effect of intensive therapy on the development and progression of diabetic nephropathy in the Diabetes Control and Complications Trial. Kidney Int 47:1703-1720

13. Brownlee M (1994) Lilly Lecture 1993. Glycation and diabetic complications. Diabetes 43:836-841

14. Soulis T, Cooper ME, Vranes D, Bucala R, Jerums G (1996) Effects of aminoguanidine in preventing experimental diabetic nephropathy are related to the duration of treatment. Kidney Int 50:627-634

15. Forbes JM, Soulis T, Thallas V et al. (2001) Renoprotective effects of a novel inhibitor of advanced glycation. Diabetologia 44:108-114

16. Yamamoto Y, Kato I, Doi T et al. (2001) Development and prevention of advanced diabetic nephropathy in RAGEoverexpressing mice. J Clin Invest 108:261-268

17. Degenhardt TP, Alderson NL, Arrington DD et al. (2002) Pyridoxamine inhibits early renal disease and dyslipidemia in the streptozotocin-diabetic rat. Kidney Int 61:939950

18. Miyata T, Ypersele de Strihou C van, Ueda Y et al. (2002) Angiotensin II receptor antagonists and angiotensinconverting enzyme inhibitors lower in vitro the formation of advanced glycation end products: biochemical mechanisms. J Am Soc Nephrol 13:2478-2487 
19. Forbes JM, Cooper ME, Thallas V et al. (2002) Reduction of the accumulation of advanced glycation end products by ACE inhibition in experimental diabetic nephropathy. Diabetes 51:3274-3282

20. Cooper ME, Allen TJ, O'Brien RC et al. (1988) Effects of genetic hypertension on diabetic nephropathy in the ratfunctional and structural characteristics. J Hypertens 6:1009-1016

21. Bunag RD (1973) Validation in awake rats of a tail-cuff method for measuring systolic pressure. J Appl Physiol 34:279-282

22. Allen TJ, Cooper ME, O'Brien RC, Bach LA, Jackson B, Jerums G (1990) Glomerular filtration rate in streptozocininduced diabetic rats. Role of exchangeable sodium, vasoactive hormones, and insulin therapy. Diabetes 39:11821190

23. Saito T, Sumithran E, Glasgow EF, Atkins RC (1987) The enhancement of aminonucleoside nephrosis by the co-administration of protamine. Kidney Int 32:691699

24. Hewitson TD, Darby IA, Bisucci T, Jones CL, Becker GJ (1998) Evolution of tubulointerstitial fibrosis in experimental renal infection and scarring. J Am Soc Nephrol 9:632-642

25. Rumble JR, Cooper ME, Soulis T et al. (1997) Vascular hypertrophy in experimental diabetes. Role of advanced glycation end products. J Clin Invest 99:10161027

26. Cao Z, Bonnet F, Candido R et al. (2002) Angiotensin type 2 receptor antagonism confers renal protection in a rat model of progressive renal injury. J Am Soc Nephrol 13:1773-1787

27. Bonnet F, Kawachi H, Koike H et al. (2000) Cloning of rat nephrin: expression in developing glomeruli and in proteinuric states. Kidney Int 57:1949-1961

28. Youssef S, Nguyen DT, Soulis T et al. (1999) Effect of diabetes and aminoguanidine therapy on renal advanced glycation end-product binding. Kidney Int 55:907916

29. Wrobel K, Garay-Sevilla ME, Nava LE, Malacara JM (1997) Novel analytical approach to monitoring advanced glycosylation end products in human serum with on-line spectrophotometric and spectrofluorometric detection in a flow system. Clin Chem 43:1563-1569

30. Snedecor GW, Cochran WG (1980) Statistical methods. In: Snedeker GW (ed.) Statistical methods, 7th edn. Iowa State University Press, Ames, Iowa, pp 228-236

31. Cooper ME (2001) Interaction of metabolic and haemodynamic factors in mediating experimental diabetic nephropathy. Diabetologia 44:1957-1972

32. Cao Z, Cooper ME, Wu LL et al. (2000) Blockade of the renin-angiotensin and endothelin systems on progressive renal injury. Hypertension 36:561-568

33. Davis BJ, Cao Z, De Gasparo M, Kawachi H, Cooper ME, Allen TJ (2003) Disparate effects of angiotensin II antagonists and calcium channel blockers on albuminuria in experimental diabetes and hypertension: potential role of nephrin. J Hypertens 21: 209-216

34. Ruiz-Ortega M, Gomez-Garre D, Alcazar R et al. (1994) Involvement of angiotensin II and endothelin in matrix protein production and renal sclerosis. J Hypertens [Suppl 12]:S51-S58

35. Wolf G, Neilson EG (1993) Angiotensin II as a renal growth factor. J Am Soc Nephrol 3:1531-1540

36. Ziyadeh FN, Sharma K (1995) Role of transforming growth factor-beta in diabetic glomerulosclerosis and renal hypertrophy. Kidney Int [Suppl 51]:S34-S36
37. Soulis-Liparota T, Cooper M, Papazoglou D, Clarke B, Jerums G (1991) Retardation by aminoguanidine of development of albuminuria, mesangial expansion, and tissue fluorescence in streptozocin-induced diabetic rat. Diabetes 40:1328-1334

38. Wilkinson-Berka JL, Kelly DJ, Koerner SM et al. (2002) ALT-946 and aminoguanidine, inhibitors of advanced glycation, improve severe nephropathy in the diabetic transgenic (mREN-2)27 rat. Diabetes 51:3283-3289

39. Vlassara H, Striker LJ, Teichberg S, Fuh H, Li YM, Steffes M (1994) Advanced glycation end products induce glomerular sclerosis and albuminuria in normal rats. Proc Natl Acad Sci USA 91:11704-11708

40. Brownlee M, Cerami A, Vlassara H (1988) Advanced glycosylation end products in tissue and the biochemical basis of diabetic complications. N Engl J Med 318:13151321

41. Mott JD, Khalifah RG, Nagase H, Shield CF 3rd, Hudson JK, Hudson BG (1997) Nonenzymatic glycation of type IV collagen and matrix metalloproteinase susceptibility. Kidney Int 52:1302-1312

42. Onozato ML, Tojo A, Goto A, Fujita T, Wilcox CS (2002) Oxidative stress and nitric oxide synthase in rat diabetic nephropathy: effects of ACEI and ARB. Kidney Int 61:186-194

43. Makita Z, Radoff S, Rayfield EJ et al. (1991) Advanced glycosylation end products in patients with diabetic nephropathy. N Engl J Med 325:836-842

44. Soulis T, Cooper ME, Sastra S et al. (1997) Relative contributions of advanced glycation and nitric oxide synthase inhibition to aminoguanidine-mediated renoprotection in diabetic rats. Diabetologia 40:1141-1151

45. Luimula P, Ahola H, Wang SX et al. (2000) Nephrin in experimental glomerular disease. Kidney Int 58:1461-1468

46. Kelly DJ, Aaltonen P, Cox AJ et al. (2002) Expression of the slit-diaphragm protein, nephrin, in experimental diabetic nephropathy: differing effects of anti-proteinuric therapies. Nephrol Dial Transplant 17:1327-1332

47. Zatz R, Meyer TW, Rennke HG, Brenner BM (1985) Predominance of hemodynamic rather than metabolic factors in the pathogenesis of diabetic glomerulopathy. Proc Natl Acad Sci USA 82:5963-5967

48. Rumble JR, Doyle AE, Cooper ME (1995) Comparison of effects of ACE inhibition with calcium channel blockade on renal disease in a model combining genetic hypertension with diabetes. Am J Hypertens 8:53-57

49. Kelly DJ, Gilbert RE, Cox AJ, Soulis T, Jerums G, Cooper ME (2001) Aminoguanidine ameliorates overexpression of prosclerotic growth factors and collagen deposition in experimental diabetic nephropathy. J Am Soc Nephrol 12:2098-2107

50. Yang CW, Vlassara H, Peten EP, He CJ, Striker GE, Striker LJ (1994) Advanced glycation end products up-regulate gene expression found in diabetic glomerular disease. Proc Natl Acad Sci USA 91:9436-9440

51. Twigg SM, Cao Z, McLennan SV et al. (2002) Renal connective tissue growth factor induction in experimental diabetes is prevented by aminoguanidine. Endocrinology 143:4907-4915

52. Oldfield MD, Bach LA, Forbes JM et al. (2001) Advanced glycation end products cause epithelial-myofibroblast transdifferentiation via the receptor for advanced glycation end products (RAGE). J Clin Invest 108:1853-1863

53. Kelly DJ, Wilkinson-Berka JL, Allen TJ, Cooper ME, Skinner SL (1998) A new model of diabetic nephropathy with progressive renal impairment in the transgenic (mRen-2)27 rat (TGR). Kidney Int 54:343-352 